\title{
Understanding the outsourcing decision in South Africa with regard to ICT
}

\author{
K.A. Johnston*, T. Abader, S. Brey and A. Stander \\ Department of Information Systems, University of Cape Town, \\ Private Bag, Rondebosch 7701, Republic of South Africa \\ Kevin.Johnston@uct.ac.za
}

Received October 2008

\begin{abstract}
Information and Communication Technology (ICT) outsourcing is a strategic initiative adopted by many organisations across all industries. Outsourcing is seen as a means for organisations to concentrate and improve their core business functions. Despite the vastly dynamic environment businesses operate in, few global studies have uncovered the factors influencing outsourcing decisions, thus the need for this paper. The research was performed using a number of statistical tests and descriptive analysis methods to explore the literature and to determine the current status of South Africa's ICT outsourcing market. Key findings reveal that cost is the most influential factor when deciding whether to outsource or not, irrespective of organisations size or type. Other important factors include concentrating on core-functions, and the availability of in-house expertise. The form of outsourcing used is not affected by the size of the organisation. Application Service Providers (ASP) is the most common form, followed by co-sourcing.
\end{abstract}

*To whom all correspondence should be addressed.

\section{Introduction}

With Information and Communication Technologies (ICTs) being ubiquitous, companies are more and more utilising them, irrespective of their core business functions. However, such technological resources might not always be available, thus the need to outsource to deal with this limitation. Outsourcing can be defined as the strategic use of external resources to perform one or more organisational activities (Drezner, 2004). ICT outsourcing has evolved from a costsaving initiative towards a more strategic objective, (Ketler \& Willems, 1999) due to constantly changing business environments and market pressures. In doing so, organisations aim at leveraging their competitiveness (Thoms, 2004). This proves that organisations are clearly aware of the benefits produced through outsourcing. Nevertheless they are still faced with the decisions of whether to outsource, what to outsource and how to outsource (Costa, 2001).

In essence, the outsourcing phenomenon has been widely researched over the past decade, but the outsourcing methods as well as the factors influencing the outsourcing decisions are evolving. In addition, South African businesses are increasingly becoming integrated into the international community (Maxwell, 2008). The need to investigate how and why SA companies structure their outsourcing plan therefore prevails. The knowledge gathered through such a study might inform other SA organisations about how to best undertake their outsourcing activities with fewer risks.
The aim of this research paper is thus to explore the current factors influencing a South African organisation's decision to outsource. The most commonly outsourced ICT functions will also be revealed. Finally, the study evaluates the impact of organisational size and type on the outsourcing decision.

This research has undertaken through a positivist and quantitative stance, employing descriptive analysis and a number of statistical tests to determine the status of South Africa's ICT outsourcing market. Data collection was guided by the survey method, using questionnaires.

Key findings reveal that cost is the most influential factor in the outsourcing decision. No correlation was however found between organisational size/type and outsourcing and the form of outsourcing used is also not affected by the size of the organisation.

\section{Literature review}

This section provides a review of the literature so as to uncover the factors influencing organisations increasing use of ICT outsourcing. For the purpose of this paper, outsourcing will be defined as the strategic use of external resources to perform one or more organisational activities (Dibbern, Goles, Hirschheim \& Jayatilaka, 2004; Scardino, Anderson, Brown, Da Rold, Dreyfuss, Karamouzis, Lovelock, Maurer, Moore \& Young, 2005). 


\section{Background to outsourcing}

The knowledge economy is ICT oriented and organizations are in constant need of high levels of knowledge and skills to remain abreast. Some therefore seek to achieve this high business value and expertise through outsourcing, and are willing to share their goals, strategies and objectives with external vendors (Scardino et al., 2005; Meyers, 2002). But what are those business functions being outsourced?

\section{ICT functions being outsourced}

Dibbern et al. (2004) categorise ICT functions into commodities, differentiators or strategic functions. They claim that common outsourced ICT functions include project management, systems and network implementation as well as business and systems planning or analysis. Infrastructure is however one of the most mature outsourced functions within an organisation. It encompasses the outsourcing of networks, systems, data centres and desktop services (Scardino et al., 2005). Furthermore, infrastructure, more specifically network outsourcing, allows organisations to focus on their core business functions as well as on the optimisation of current infrastructures for cost reductions (Scardino et al., 2005).

Business Process Outsourcing in turn includes outsourcing of entire business functions ranging from a project inception up until implementation or support and maintenance to third party vendors (Cantara et al., 2005; Da Rold, Jester \& Young, 2005; Dibbern et al., 2004). It allows organisations to focus on their core business functions, streamline and integrate processes, and reduce operational costs (Cantara et al., 2005). Industries associated with the outsourcing of entire business processes include governments, financial and accounting services, health care, and logistics organisations (Dibbern et al., 2004). Outsourcing initiatives are typically influenced by some factor(s) which arise from internal or external pressures. However, according to Wonseok, Gallivan and Kim (2006), there is a correlation between the method and outsourcing function and the level of switching costs and strategic importance of the function (Wonseok et al., 2006). Factors influencing the outsourcing decisions are further explored in the next section.

\section{Factors influencing the decision to outsource}

Studies performed at international levels reveal that factors influencing an organisation's decision to outsource have evolved from being a cost-saving initiative to a strategic objective (Costa, 2001; Goo, Kishore \& Rao, 2000; Meyers, 2002). Such decisions are said to be based on the need for exposure to additional skills and expertise, political factors (promoting self-interest and following of trends), and access to best practices and improving staffing flexibility (Benamati \& Rajkumar, 2002; Costa, 2001; Fink \& Shoeib, 2003; Meyers, 2002). Many outsourcing decisions are also based on prior outsourcing experiences (Benamati \& Rajkumar, 2002). Different factors pertaining to the outsourcing decision, as described in literature are discussed below. They relate to Cost Control, Concentration on core business function, in-house expertise, risk management and legal factors.

\section{Costs control}

Due to significant growth, ICT services in higher-cost areas are continuously challenged by competition from low-cost countries viz. India, and Canada (Scardino et al., 2005). However, the reported cost-savings incurred from the outsourcing process is only an indirect benefit while the direct impact lies in the reduction of personnel, cheaper labour, and more productive personnel i.e. concentrating on core business functions, lower total cost of ownership (TCO) and stabilising the increase in workload (Brody, Miller \& Rolleri, 2004; Costa, 2001; Dibbern et al., 2004; Hormozi, Hostetler \& Middleton, 2003; Thoms, 2004). However, according to the Global Outsourcing Report (Minevich \& Richter, 2005), South Africa already was already marked as "global opportunity"for IT offshore investment (in 2005). It is therefore interesting to investigate on what are these factors related to cost, which urge SA companies to outsource while the country itself is considered as being competitive.

\section{Concentration on core business functions and strategic advantage}

Outsourcing, initially seen as an opportunity for organisations to downsize and reduce costs, has now developed into a strategic tool which impacts on corporate innovativeness, profitability and investments (Goo et al., 2000; Ketler \& Williams, 1999). It can be seen as an opportunity to promote strategic alliances through partnership building especially since relationship management is a major success factor within the business environment (Sargent, 2006).

Organisations further enhance their competitive advantage by outsourcing of both core and non-core functions. These functions might be outsourced due to the lack of necessary resources to develop core functions. The potential gain from outsourcing the relevant core function may also be greater than that obtained from in-house resources (Costa, 2001; Thoms, 2004). Consequently, the decision of what to outsource, core, non-core or both, is dependent on the organisation's environment rather than on the nature of the function (Bloch \& Spang, 2003; Thoms, 2004). The impact of South African business environments on outsourcing decisions should thus be studied as no such research has been undertaken to date.

\section{In-house expertise}

Organisations tend to outsource their ICT functions in order to reduce uncertainty and remain competitive (Wonseok et al., 2006). Costa (2001) expands this notion by explaining that the attempt to develop in-house skills or attracting individuals with the necessary skills is costly and time consuming, thus the need to outsource. Further studies should however be undertaken to investigate whether this is also valid in a South African business environment.

\section{Risk management}

Potential risks being faced by organisations while outsourcing, has a major impact on the outsourcing decision. 
Issues encountered include the potential loss of control, complexity of infrastructure, division of labour, and cultural and language barriers (Benamati \& Rajkumar, 2002; Lee, Huynh, Kwok, Pi, 2003; Ketler \& Willems, 1999). Ramanujan and Jane (2006) and Parlov (2004) further add that other tangible and intangible issues incurred are often unnoticed by the client. These include breach of privacy, inferior quality and performance, and other hidden costs like cultural issues and contract management issues. These issues pose a high level of risk to the client if not well documented and understood. However, Goo et al. (2000) argue that organisations occasionally outsource their ICT functions in order to transfer any risks incurred during inhouse development, implementation or analysis to their outsourcing vendor. These studies having been performed internationally provided an external perspective on risk management during outsourcing. A South African perspective would be quite useful to local organisations wishing to outsource.

\section{Legal factors}

Organisations wishing to outsource usually mistake the terms and conditions of offshore outsourcing as being the same as that of inshore outsourcing (Huntley, 2006). This misconception usually leads investors to overlook the legal and regulatory compliances of the country being outsourced to. Issues like breach of privacy, corporate law and taxation issues of the relevant country, permits and licenses, and regulatory issues are often not well detailed or understood by the client (Ramanujan \& Jane, 2006). It is therefore important to understand whether South African companies are aware of such legal implications while deciding to outsource, so that their future decisions are better informed.

Having identified the factor(s) influencing an organisations outsourcing decisions, the next section evaluates which outsourcing method is most efficient and effective, based on the organisations environment and strategic needs.

\section{Types of outsourcing}

Numerous outsourcing methods have been developed to accommodate the changing business environment. These methods are tailored to the environmental requirements of the outsourcing objectives. As one objective of this study is to determine which form of outsourcing is used the most and if the size of the organisation has an effect on which form is used, it is important to understand what are the different existing forms currently implemented worldwide.

\section{Offshoring}

Offshoring emphasises on the process, which includes the relocation of the business processes to lower costs or strategically advantageous locations outside national borders (Erber \& Sayed-Ahmed, 2005; Thoms, 2004). Despite cultural dissimilarities, language barriers and time-zone differences offshoring taps into a wider and more global labour pool, which is necessary to the delivery of cost benefits, skills and scalability, demanded by clients (Iyengar, Karamouzis, Marriott \& Young, 2006).

\section{Inshoring}

Inshoring of business functions is similar to offshoring, but both vendor and client remain within the same national borders (Erber \& Sayed-Ahmed, 2005; Scardino et al., 2005; Thoms, 2004). Researchers agree that inshoring adds to the advantages available from offshoring because of the cultural similarity of employees working in the same country. In essence, this may result in fewer misunderstandings and fewer cultural barriers (Brown \& Karamouzis, 2005; Scardino et al., 2005). Inshoring has not only been instrumental in local job creations and skills development but it has also created a better quality workforce by combining both business and technical skills (Thoms, 2004)

\section{Cosourcing}

Cosourcing is a form of outsourcing whereby a third party works in conjunction with a client while the internal group transitions itself to a new set of skills. Perceived as a popular method of outsourcing within internal audit firms, it is commonly known as a transition strategy (Thoms, 2004). A survey conducted by Serafini, Sumners, Apostolou and Lafleur (2003) showed that cosourcing was used by $44 \%$ of the respondents, who derived benefits like specialized knowledge, technical skills, staffing flexibility and best practices. However, in spite of these acquired benefits, vendors risk tying their profit to the performance of the client or organisation acquiring the cosourcing services (Cullen \& Willcocks, 2003; Dibbern et al., 2004).

\section{Smartsourcing}

Smartsourcing is seen as a strategic form of outsourcing where organisations use a combination of inshoring and offshoring. In doing so, organisations retain control over their core activities and can commission the relevant activities to third parties (Wright, 2005). Koulopoulos (2004) adds that within a smartsourcing partnership between client and vendor, the vendor oversees the operational excellence and cost reductions within the organisation while the client refocuses its attention to the core innovative activities within the organisation.

\section{Application service providers (ASP)}

While not considered as an actual outsourcing method, ASP is as a multiyear or annuity relationship, which involves the transfer of daily management responsibility of custom or packaged applications to an external service provider (Anderson, 2006). Similar to the outsourcing principles, ASP's focus is to provide fast, predictable, cost-effective functionality, thus allowing the client to focus on core business functions, access best practices or processes, cost savings and better control of legacy systems (Young et al., 2005). Huntley (2006) found ASP's have recorded a relatively strong satisfaction rate from a surveyed sample of 343 organisations. These findings complement the rapid adoption rate of ASP's. 
In the next section, an overview of the relationship between organisational size and type and outsourcing will be provided, as reported in literature.

\section{Relationship between organisational size / type and outsourcing}

Organisations across industries are adopting outsourcing as the benefits incurred are more and more attractive (Fulbright \& Routh, 2004). However, the effectiveness of outsourcing and the methods used may be dependant upon the organisational type or size (Fulbright \& Routh, 2004).

\section{Organisational type}

The retail market has steadily built a presence within ICT outsourcing. A study conducted by Waller, (2004) revealed that a supply chain initiative outsourced by the retailer has seen 3\% improvements, reduced inventory levels and order cycle times. Cusmano, Mancusi and Morrison (2006) add that internationalisation of production and emergence of global-reaching innovative activities are amongst the drivers of recent transformations at business and systems level. Furthermore, outsourcing within the manufacturing and production industry is driven by factor price differences across countries and regions, as well as the commitment to internal resources in order to focus on core business functions (Cusmano et al., 2006).

\section{Organisational size}

Studies have revealed that outsourcing decisions within small-to-medium enterprises (SME) are driven by similar factors within large enterprises viz. cost, personal connections, access to a mass of skilled technical professionals and project management skills (Coward, 2003). Given similarities of outsourcing between SME's and large corporations, SME's however differ with regards to the specific outsourcing method they choose to adopt. With reference to software development outsourcing, Coward (2003) claims that SME's typically outsource to vendors close to home (within the relevant country) as they require a close cooperation between themselves and the vendor. This cooperation can only be achieved via frequent resolution of problems without language or cultural barriers.

A survey covering 1100 SMEs in the US was conducted by TEC International to determine the popularity of offshore outsourcing (Olsen, 2006). Results of this study indicated that at the time, only $5 \%$ intended to outsource ICT jobs overseas. Of these SME's, $12 \%$ claimed that they planned to outsource their manufacturing jobs while $73 \%$ claimed that they had no intention of engaging in offshore outsourcing. Furthermore, it was found that $19 \%$ of all organisations have an offshore outsourcing strategy. With the SME market representing the bulk of the market for both the US and South Africa, it can be assumed that offshoring may not be as large as it is portrayed (Olsen, 2006). Despite the low levels of offshoring encountered by SME's, smaller firms are more likely to outsource i.e. within or to a neighbouring country as they can rely on scale economies (Carr, 2005).
Having reviewed literature on different aspects of outsourcing, the next section details the research methodology employed during this study.

\section{Research design}

This section describes and justifies the research approach, research propositions, data gathering techniques and sample selection. The data analysis method employed is also discussed, followed by a brief overview of the limitations of the research.

\section{Purpose of research}

The purpose of this research was to obtain an understanding of outsourcing in South Africa; which business functions are being outsourced and what influences the outsourcing decisions. Different aspects of outsourcing were taken into account and tested against different sizes/types of organisations for relationships. This was done to determine how influential the different business aspects can be on outsourcing.

\section{Quantitative research approach}

For the purpose of this study, a quantitative research approach was adopted. This enabled researchers to effectively test the various hypotheses and objectives regarding the outsourcing decisions in South Africa as well as to establish patterns of relationships between the various variables of interest.

\section{Research objectives}

As highlighted in the introduction, the primary purpose of this empirical research project was to study the decision to outsource. This was further fragmented into objectives which were utilised to provide insight as to what the study aimed to accomplish.

These objectives are as follows, to:

- Determine which business ICT functions are outsourced the most.

- Determine which factors influence the outsourcing decision the most.

- Determine which form of outsourcing is mostly used and if the size of the organisation has an effect on the form used.

- Determine if there is any relationship between the size/type of a business, what they outsource or what influences their outsourcing decision.

Firstly, this study intended to answer research questions regarding the business functions and the significance of outsourcing for each function. In doing so, the purpose was to accurately discover which functions are being outsourced.

- What are the most outsourced ICT business functions?

- To what extent are they outsourced? 
Another primary objective of this empirical research project was to determine what influences the outsourcing decisions; why are companies outsourcing? What are the influencing factors behind the decision? And how important are they when making the decision? The following research questions were designed to ascertain the degree of influence that these factors have on the decision to outsource.

- What are the most influencing factors when making a decision regarding outsourcing?

- To what extent do they influence the decision?

Other objectives of this research were to determine if there is any correlation between the size of the business and its outsourcing decision as well as between the type of the business and its outsourcing decision. The following hypotheses were drawn up to test this possibility.

- $\mathrm{H}_{1}$ : The size of the business does not affect the extent to which business functions are outsourced

- $\mathrm{H}_{2}$ : The size of the business does not affect which factors influence the outsourcing decision

- $\mathrm{H}_{3}$ : The type of the business does not affect the extent to which each business function is outsourced

- $\mathrm{H}_{4}$ : The type of the business does not affect the extent to which each factor influences the outsourcing decision

- $\mathrm{H}_{5}$ : The size of the business does not affect which form of outsourcing is used

\section{Study design}

The philosophical orientation was positivistic. The underlying principle of a positivistic philosophy is that the external reality can be objectively known and measured (Blumberg, Cooper \& Schindler, 2005). Blumberg, et al. (2005) adds that positivism aims to develop knowledge by investigating the reality through theory and observing objective facts. Thus positivism proved to be a good-fit for quantitative analysis.

\section{Subjects}

A Judgement Sampling methodology was employed while selecting the sample population (Blumberg et al., 2005). The research study focused on decision-makers regarding ICT outsourcing in South African organisations. Fifty percent of respondents were taken from national lists such as the Johannesburg Stock Exchange, and the Chamber of Commerce, and 50\% were from private contact lists of UCT academics.

The target population was Information Technology (IT) managers having a good understanding of the business' position with respect to its outsourcing decisions. The questionnaires were distributed via email, fax and post.
To ensure an accurate representation of the sample population, organisations of varying sizes viz. small (less than 50 employees), medium (more than 50, less than 200 employees) and large (more than 200 employees) were approached.

\section{Table 1: Questionnaire response rate}

\begin{tabular}{l|c|c|c}
\hline & $\begin{array}{c}\text { 1st distribution } \\
\text { session }\end{array}$ & $\begin{array}{c}\text { 2nd distribution } \\
\text { session }\end{array}$ & Total \\
\hline Questionnaire & 919 & 890 & 1809 \\
\hline Forms Returned & 80 & 78 & 158 \\
\hline Usable & 50 & 78 & 128 \\
\hline Unusable & 30 & 0 & 30 \\
\hline
\end{tabular}

(Source: Ketler \& Willems, 1999)

Table 1 illustrates the response rate obtained from distributing 1809 questionnaires. A study conducted by Ketler and Willems (1999) showed that the response rate the researchers should anticipate is as low as 9\%. A low response rate of $8.7 \%$ was obtained, roughly in line with the response rate experienced by Ketler and Willems (1999).

\section{Data collection}

This section outlines the research instrument being adopted, its composition and how it was implemented.

\section{Instrument design}

Due to the quantitative nature of this research study, researchers have found that the most effective and efficient instrument for this project would be a questionnaire. The questionnaire consisted of close-ended questions in order to simplify the interpretation of the findings and to ensure simplicity and timeliness for participants. The questions were a combination of Likert Scale and checkbox type questions; all questions were designed to answer the research questions or enable suitable testing of the hypotheses.

The Business Functions being outsourced were investigated by asking respondents to rate each of them from a range of Not at All [1], Somewhat [2], Average [3], More than Average [4], and Substantially [5]. The different business functions investigated included Project Management, Risk Management, Software Development, Business Analysis, Systems Analysis, Business Consulting, Systems Consulting, Hardware Implementation, Systems Implementation, and Network Implementation. The respondents were also required to rate the percentage to which they outsource each of those ICT functions on a scale of $0 \%, 0-10 \%, 10-25 \%$, 25-50\%, 50-75\%, and 75-100\%.

The business type was investigated by requesting the respondents to rate themselves as either of those organisation types: Retail, ICT, Consulting, Wholesale, Distribution, Manufacturing, Accounting/Finance, and Other (any answer provided by the respondent was acceptable).

The different factors derived from literature and which might influence the outsourcing decisions were also 
measured within the South African context using the questionnaire. They include Cost, Legal Factors, In-House Expertise, Strategic Advantage, Business needs to concentrate on core functions, and Risk. The respondents were asked to rate the importance of these factors in influencing their outsourcing decision, as being either Unimportant [1], Somewhat Important [2], Undecided [3], Somewhat Important [4], Very Important [5].

The form of outsourcing employed was investigated by asking the respondents to choose any of these options: Offshoring, Inshoring, Co-Sourcing, Smartsourcing, and Application Service Providers.

Finally, the organisation size was measured by asking the respondents to rate their number of employees as being either Small (<50), Medium (50-200), or Large (>200).

\section{Research findings}

The results generated during this study are next presented, without any inference to the implications, which will later be discussed.

\section{Respondent analysis}

For the purpose of this empirical research project, data was gathered from South African organisations. 50\% of the respondents were from large organisations, while $35 \%$ and $15 \%$ were from small and medium sized enterprises respectively.

Some of the respondents considered that their company did not fall under any of the categories suggested in the questionnaire; and thus selected the 'other' option. It can be noted that 'other' accounts for 16 of the 72 responses, while consulting accounts for 15 . The other top two organisational types are accounting/finance (12) and ICT (11). Data from the other organisational types (Retail, Wholesale, Distribution, and Manufacturing) have not been included in the data analysis tests (Kruskal-Wallis), due to their limited number of responses, which would otherwise affect the integrity of the results.

Table 2 displays the replies, separated into organisational size type as well as their frequency of return.

$86 \%$ of the results were obtained from small and large organisations while medium firms only accounted for $14 \%$ of the results. This provides a good general reflection of the respondents. Furthermore, Table 2's results show that the top four types of firms have greater influence on the results. It is therefore valid to note that, for the sake of this empirical research project, most accurate results would be obtained from small and large ICT, accounting/finance, consulting and other organisations.
Table 2: Frequency of replies

\begin{tabular}{c|l|c|l}
\hline Size & \multicolumn{1}{|c|}{ Type } & Frequency & Percentage \\
\hline \multirow{5}{*}{ Small } & Retail & 2 & 8 \\
\cline { 2 - 4 } & ICT & 6 & 24 \\
\cline { 2 - 4 } & Consulting & 7 & 28 \\
\cline { 2 - 4 } & Wholesale & 1 & 4 \\
\cline { 2 - 4 } & Distribution & 1 & 4 \\
\cline { 2 - 4 } & Accounting/Finance & 3 & 12 \\
\cline { 2 - 4 } & Other & 5 & 20 \\
\cline { 2 - 4 } & & 25 & (of small) \\
\hline \multirow{5}{*}{ Medium } & ICT & 2 & 18,2 \\
\cline { 2 - 4 } & Consulting & 1 & 9 \\
\cline { 2 - 4 } & Wholesale & 1 & 9 \\
\cline { 2 - 4 } & Distribution & 1 & 9 \\
\cline { 2 - 4 } & Manufacturing & 2 & 18,2 \\
\cline { 2 - 4 } & Accounting/Finance & 2 & 18,2 \\
\cline { 2 - 4 } & Other & 2 & 18,2 \\
\cline { 2 - 4 } & & 11 & $($ of medium) \\
\hline \multirow{5}{*}{ Large } & Retail & 5 & 13,9 \\
\cline { 2 - 4 } & ICT & 3 & 8,3 \\
\cline { 2 - 4 } & Consulting & 7 & 19,4 \\
\cline { 2 - 4 } & Distribution & 1 & 2,7 \\
\cline { 2 - 4 } & Manufacturing & 4 & 11,1 \\
\cline { 2 - 4 } & Accounting/Finance & 7 & 19,4 \\
\cline { 2 - 4 } & Other & 9 & 25 \\
\cline { 2 - 4 } & & 36 & (of large) \\
\hline & & &
\end{tabular}

Consisting of 72 respondents, the research sample was relatively small and therefore could not be used as a representation of the entire market. It however provided a basic understanding of the current situation in the market and opened doors for further study with larger samples.

\section{Process of analysis}

The research questions were answered through inferential analysis. Hypotheses, $\mathrm{H} 1$ and $\mathrm{H} 2$ compared the size of the business to the various outsourcing questions, while H3 and $\mathrm{H} 4$ compared the type of the organisation to the various outsourcing questions. To test these hypotheses, the statistical analysis methods chosen were Spearman correlation and Kruskal-Wallis, respectively. H5 compares the size of the organisation to the form of outsourcing used to determine if there is a relationship between the two variables. The chi-squared test will be used to test $\mathrm{H} 5$.

\section{Reliability analysis}

The reliability of the constructs used in the questionnaire was measured using Cronbach alpha. Generally, the Cronbach alpha value for a particular construct should be 0.7 or above for that construct to be deemed reliable (Hart, 2006).

For all outsourced functions, the values were above 0,7 ; near to 0,9 thus indicating that all variables are reliable for tests regarding outsourced functions. They include Project management (0,886662), Risk Management (0,894106), Software Development (0,898504), Business Analysis (0,892044), Systems Analysis (0,879535), Business Consulting (0,896693), Systems Consulting (0,87535), Hardware Implementation (0,889604), Systems 
Implementation (0,88229), and Network Implementation $(0,89935)$.

The Cronbach alpha values for the variables to be used with regards to the factors affecting the outsourcing decision were all also above 0,7 , with Cost $(0,859436)$, Legal Factors (0,853958), In-house expertise (0,85860), Strategic advantage $(0,852953)$, Business need to concentrate on core functions $(0,846752)$ and Risk $(0,847731)$.

Due to the exploratory nature of the research, the Cronbach alpha value should be $>0,6$ (Hart, 2006). The average Cronbach alpha value obtained for all the variables is 0,849993 , thus confirming that the variables are reliable and should provide accurate results. These variables were used during the analysis of the size and type of the organisation.

\section{Descriptive analysis}

\section{Outsourced ICT business functions}

The first two research questions were: What are the most outsourced ICT business functions?' and 'To what extent are they outsourced?' The respondents were required to state how much they outsource a particular ICT business function from a provided list of ranges as previously described. The midpoints of each of these ranges were calculated and used so that an average level of outsourcing could be obtained.

The results showed that the most outsourced ICT business function is Network Implementation (59.84), and the least outsourced function is Risk Management (19.44). Software Development (54.77), Hardware Implementation (50.48) and Systems Implementation (48.89) form the remainder of the four most outsourced functions. This is summarised in the Table 3 .

\section{Factors influencing the outsourcing decision}

The next two research questions asked were: 'What are the most influencing factors when making a decision regarding outsourcing?' and 'To what extent do they influence the decision?'

Table 3: Average level of outsourcing for outsourced function

\begin{tabular}{l|c}
\hline \multicolumn{1}{c|}{ Outsourced Function } & Average Level \\
\hline Network Implementation & 59,84 \\
\hline Software Development & 54,77 \\
\hline Hardware Implementation & 50,48 \\
\hline Systems Implementation & 48,89 \\
\hline Systems Consulting & 36,87 \\
\hline Systems Analysis & 32,62 \\
\hline Business Consulting & 25,31 \\
\hline Project Management & 24,96 \\
\hline Business Analysis & 23,53 \\
\hline Risk Management & 19,44 \\
\hline
\end{tabular}

In Table 4, the weighted average has then been separated according to organisation sizes. The result suggest that the medium sized organisations contributed the least to this study (15\%), however, medium sized organisations still outsource all ICT business functions to the greatest extent, except with regards to Network and Hardware Implementation.

Table 4: The extent to which the different size of organisations outsource their ICT functions

\begin{tabular}{l|l|l|l}
\hline & Small & Medium & Large \\
\hline Project Management & 19,09 & 31,94 & 26,9 \\
\hline Risk Management & 19,77 & 21,04 & 18,73 \\
\hline Software Development & 42,63 & 80,26 & 55,39 \\
\hline Business Analysis & 20 & 27,53 & 24,77 \\
\hline Systems Analysis & 26,29 & 46,49 & 32,78 \\
\hline Business Consulting & 22,4 & 36,99 & 23,81 \\
\hline Systems Consulting & 27,66 & 57,92 & 36,82 \\
\hline Hardware Implementation & 51,09 & 47,27 & 51,03 \\
\hline Systems Implementation & 45,37 & 54,8 & 49,52 \\
\hline Network Implementation & 57,26 & 49,61 & 64,77 \\
\hline
\end{tabular}

The respondents were provided with a list and required to choose which factors influenced their outsourcing decisions. A Likert scale was provided with values ranging from 1 to 5 (Unimportant to Very Important). From these values, averages were calculated to determine what are the most influencing factors and to what extent they influence the organisations' decisions regarding outsourcing. All values have been adjusted out of 100 . Based on the research findings the most influential factor is Cost (86.60), and the least influential factor is 'Legal Factors' (65.20). The remainder of the top three factors include 'the need to concentrate on core business functions' (84.00) and the availability of in-house expertise (82.20). This may be due to the fact that the lack of in-house expertise causes the organisations to consider outsourcing. The average figures were then separated into organisational sizes.

Table 5: The extent to which the different size organisations are influenced by the factors

\begin{tabular}{l|l|l|l}
\hline Influencing Factor & Small & Medium & Large \\
\hline Cost & 88,00 & 89,09 & 85,00 \\
\hline Legal Factors & 71,20 & 54,55 & 64,44 \\
\hline In-House expertise & 80,80 & 83,64 & 82,78 \\
\hline Strategic Advantage & 76,80 & 76,36 & 80,00 \\
\hline Concentrate on core functions & 86,40 & 84,00 & 82,22 \\
\hline Risk & 86,40 & 69,09 & 78,33 \\
\hline
\end{tabular}

Table 5 illustrates the extent to which each factor influences the various organisational sizes. The only noticeable difference can be noted in Legal Factors and Risk. According to the results from Table 5, small organisations consider legal factors and risk more than medium and large organisations. This could be due to the fact that legal factors as well as risk factors have greater implications on the wellbeing of a smaller organisation. Risk is especially important as it could lead to the dissolution of the organisation if not taken into account. 


\section{Forms of outsourcing}

The result suggests that ASP is the most popular choice (42\%) when choosing a form of outsourcing. Co-sourcing is the second most used form of outsourcing (24\%), while the remaining three are used to a lesser extent, with Inshoring (13\%), Smartsourcing (11\%), and Offshoring (10\%).

\section{Hypothesis testing}

The following section analyses the results of the various hypothesis tests employed. This section is divided into three distinct subsections, each dealing with a separate type of statistical test.

\section{Spearman correlation}

Relationship between organisational size and the ICT business function(s) being outsourced

Hypotheses $\mathrm{H}_{1}$ and $\mathrm{H}_{2}$ pertained to the relationship between the size of the organisation and which ICT business functions they outsource, as well as the influencing factors when making this decision. Since the size of the organisation is ordered (small-large) the Spearman Correlation test was used.

Table 6 displays the p-values for all outsourced business functions against the size of the organisation; this test was conducted to evaluate whether there is any correlation between the size of the organisation and what they outsource $\left(\mathrm{H}_{1}\right)$ and the extent to which each function is outsourced. In order to obtain a significant interpretation, the p-value must be smaller than 0.05 .The test reveals that there is no significant correlation as all p-values are above 0.05 . Although none of the outsourced business functions are significantly related to the size of the organisation, Project Management and Systems Consulting revealed the most potential to correlate to the size of the organisation. Again, the results may not be representative of the industry status due to the small sample size.

Table 6: Spearman correlation for size vs outsourced functions

\begin{tabular}{l|c|c|c|c}
\hline $\begin{array}{c}\text { Outsourced } \\
\text { Function }\end{array}$ & $\begin{array}{c}\text { Valid } \\
\text { N }\end{array}$ & $\begin{array}{c}\text { Spearman } \\
\mathbf{R}\end{array}$ & $\mathbf{t ( N - 2 )}$ & p-Level \\
\hline Project Mgmt & 72 & 0,193593 & 1,650945 & 0,10323 \\
\hline Risk Mgmt. & 72 & 0,076876 & 0,645097 & 0,520973 \\
\hline S/W Develop & 72 & 0,088262 & 0,741349 & 0,460962 \\
\hline Bus Analysis & 72 & 0,171841 & 1,459438 & 0,148918 \\
\hline Systems Anal & 72 & 0,165997 & 1,408372 & 0,163447 \\
\hline Bus Consult & 72 & 0,110373 & 0,929127 & 0,356016 \\
\hline Syst Consul & 72 & 0,193548 & 1,650546 & 0,103311 \\
\hline H/W Imp. & 72 & 0,011019 & 0,092198 & 0,926804 \\
\hline Sys.Imp. & 72 & 0,071811 & 0,602367 & 0,548876 \\
\hline N/W Imp. & 72 & 0,080814 & 0,678353 & 0,499784 \\
\hline
\end{tabular}

As all the values are positive in Table 6 it implies the extent does increase with size, but not significantly. Therefore, there is no significant evidence to infer that $\mathrm{H}_{1}$ should be rejected. The size of the business therefore does not affect the business functions being outsourced.
Relationship between Organisational Size and the factors that influence the outsourcing decision

$\mathrm{H}_{2}$ was tested to determine if there is any relationship between the size of the organisation and the factors influencing decision-making regarding outsourcing. The Spearman correlation test results (see Table 7) reveal no correlation between the two variables. However, next to cost, risk shows the most potential to correlate with the organisational size. This reinforces what was discovered in Table 5; smaller organisations are influenced by risk to a greater extent than medium and large organisations. With the use of a larger sample, this test might have shown a significant p-value for correlation between the size of the organisation and the influencing factors.

Table 7: Spearman correlation for size vs influencing factors

\begin{tabular}{l|c|c|c|c}
\hline $\begin{array}{c}\text { Influencing } \\
\text { Factor }\end{array}$ & $\begin{array}{c}\text { Valid } \\
\mathbf{N}\end{array}$ & $\begin{array}{c}\text { Spearman } \\
\mathbf{R}\end{array}$ & $\mathbf{t}(\mathbf{N}-2)$ & p-Level \\
\hline Cost & 72 & $-0,183025$ & $-1,55761$ & 0,123837 \\
\hline Legal factors & 72 & $-0,126302$ & $-1,06525$ & 0,290425 \\
\hline $\begin{array}{l}\text { In-House } \\
\text { expertise }\end{array}$ & 72 & 0,022896 & 0,19161 & 0,8486 \\
\hline $\begin{array}{l}\text { Strategic } \\
\text { advantage }\end{array}$ & 72 & 0,05349 & 0,44818 & 0,655411 \\
\hline $\begin{array}{l}\text { Concentrate } \\
\text { on core } \\
\text { functions }\end{array}$ & 72 & $-0,144736$ & $-1,21506$ & 0,228483 \\
\hline Risk & 72 & $-0,177935$ & $-1,51285$ & 0,134819 \\
\hline
\end{tabular}

Therefore, there is no significant evidence to infer that $\mathrm{H}_{2}$ should be rejected. This is because the p-values of the Spearman correlation test are too high. The size of the business does not affect which factors influence the outsourcing decision.

Kruskal - Wallis

Relationship between the type of the organisation and the extent to which each ICT business function is outsourced

Hypotheses $\mathrm{H}_{3}$ and $\mathrm{H}_{4}$ pertained to the relationship between the type of the organisation and which ICT business functions they outsource, as well as the influencing factors when making this decision. As the 'type of the organisation' is not ordered data and there are more than three independent groups of sampled data, the Kruskal-Wallis non-parametric test proved to be most suitable.

Table 8 displays the relationship between the outsourced business functions and the organisational type $\left(\mathrm{H}_{3}\right)$. Findings show that there is no significance in any of the tests except one. The outsourcing of the various business functions have no relationship with the organisational type except for Network Implementation ( $p$-value $=0.0411$ ). 
Table 8: Kruskal-Wallis p-values for type vs outsourced functions

\begin{tabular}{l|c}
\hline Outsourced Function & p-Level \\
\hline Project Management & 0,3284 \\
\hline Risk Management & 0,5626 \\
\hline Software Development & 0,6074 \\
\hline Business Analysis & 0,6794 \\
\hline Systems Analysis & 0,7811 \\
\hline Business Consulting & 0,3473 \\
\hline Systems Consulting & 0,2587 \\
\hline Hardware Implementation & 0,6177 \\
\hline Systems Implementation & 0,1627 \\
\hline Network Implementation & $\mathbf{0 , 0 4 1 1}$ \\
\hline
\end{tabular}

Therefore, there is no significant evidence to infer that $\mathrm{H}_{3}$ should be rejected. This is because the p-values of the Kruskal-Wallis test are too high. This is true for all outsourced functions except Network Implementation; pvalue $=0,0411$, in which case there is strong evidence to infer that the null hypothesis should be rejected. The type of the business affects the outsourcing of Network Implementation.

Relationship between organisational size and the extent to which each factor influences the outsourcing decision

$\mathrm{H}_{4}$ was tested to determine if there is any relationship between the organisational type and factors influencing them when making a decision regarding outsourcing. Table 9 shows the relationship between the influencing factors and the organisational type. None of these tests revealed any significance.

Therefore, there is no significant evidence to infer that $\mathrm{H}_{4}$ should be rejected. This is because the p-values of the Kruskal-Wallis test are too high. The type of the business does not affect the extent to which each factor influences the outsourcing decision.

Chi - squared

For the fifth and final hypothesis $\mathrm{H}_{5}$, the aim was to determine if there is a relationship between the size of the organisation and the form of outsourcing used. As the aim of $\mathrm{H}_{5}$ was to determine if the samples are different enough in some characteristic to show that there is a pattern with respect to the sample, the best test to use would be the chisquared test (Connor-Linton, 2003). The results of the chisquared test can be seen in Table 10.

The p-value of 0.8096 is very high, thus implying that there is no significance. There is therefore no evidence to infer that $\mathrm{H}_{5}$ should be rejected. This is because the p-value of the Chi-Squared test is too high. The size of the business does not affect which form of outsourcing is used.
Table 9: Kruskal-Wallis p-values for Type vs Influencing Factors

COST

\begin{tabular}{|c|c|c|}
\hline \multicolumn{3}{|c|}{ Kruskal-Wallis test: $\mathrm{H}(3, \mathrm{~N}=54)=4,220008 \mathrm{p}=, 2387$} \\
\hline $\begin{array}{c}\text { Type } \\
\end{array}$ & Valid N & Sum of Ranks \\
\hline Other & 16 & 505,5000 \\
\hline Accounting/Finance & 12 & 252,0000 \\
\hline Consulting & 15 & 401,5000 \\
\hline ICT & 11 & 326,0000 \\
\hline \multicolumn{3}{|c|}{$\begin{array}{l}\text { LEGAL FACTORS } \\
\end{array}$} \\
\hline \multicolumn{3}{|c|}{ Kruskal-Wallis test: $\mathrm{H}(3, \mathrm{~N}=54)=3,552650 \mathrm{p}=, 3140$} \\
\hline Type & Valid N & Sum of Ranks \\
\hline Other & 16 & 442,5000 \\
\hline Accounting/Finance & 12 & 332,5000 \\
\hline Consulting & 15 & 337,5000 \\
\hline ICT & 11 & 372,5000 \\
\hline
\end{tabular}

IN-HOUSE EXPERTISE

Kruskal-Wallis test: $\mathrm{H}(3, \mathrm{~N}=54)=2,862336 \mathrm{p}=, 4133$

\begin{tabular}{l|c|c}
\hline \multicolumn{1}{c}{ Type } & Valid N & Sum of Ranks \\
\hline Other & 16 & 416,0000 \\
\hline Accounting/Finance & 12 & 287,0000 \\
\hline Consulting & 15 & 412,5000 \\
\hline ICT & 11 & 369,5000 \\
\hline
\end{tabular}

STRATEGIC ADVANTAGE

Kruskal-Wallis test: $\mathrm{H}(3, \mathrm{~N}=54)=1,314579 \mathrm{p}=, 7257$

\begin{tabular}{l|c|c}
\hline \multicolumn{1}{c}{ Type } & Valid N & Sum of Ranks \\
\hline Other & 16 & 463,5000 \\
\hline Accounting/Finance & 12 & 299,5000 \\
\hline Consulting & 15 & 383,0000 \\
\hline ICT & 11 & 339,0000
\end{tabular}

CONCENTRATE ON CORE FUNCTION

Kruskal-Wallis test: $\mathrm{H}(3, \mathrm{~N}=54)=1,868657 \mathrm{p}=, 6001$

\begin{tabular}{l|c|c}
\multicolumn{1}{c}{ Type } & Valid N & Sum of Ranks \\
\hline Other & 16 & 469,5000 \\
\hline Accounting/Finance & 12 & 353,5000 \\
\hline Consulting & 15 & 354,5000 \\
\hline ICT & 11 & 253,5000 \\
\hline \multicolumn{3}{c}{ RISK }
\end{tabular}

Kruskal-Wallis test: $\mathrm{H}(3, \mathrm{~N}=54)=1,703463 \mathrm{p}=, 6362$

\begin{tabular}{l|c|c}
\multicolumn{1}{c}{ Type } & Valid N & Sum of Ranks \\
\hline Other & 16 & 452,5000 \\
\hline Accounting/Finance & 12 & 337,0000 \\
\hline Consulting & 15 & 354,5000 \\
\hline ICT & 11 & 341,0000 \\
\hline
\end{tabular}

Table 10: Chi-Squared results for size vs form of outsourcing

PEARSON CHI-SQUARE: $4.49757, \mathrm{df}=8, \mathrm{p}=.809673$

\begin{tabular}{|c|c|c|c|c|c|c|}
\hline Small & 2 & 2 & 6 & 4 & 11 & 25 \\
\hline & $8,0 \%$ & $8,0 \%$ & $24,0 \%$ & $16,0 \%$ & $44,0 \%$ & \\
\hline \multirow[t]{2}{*}{ Medium } & 1 & 3 & 2 & 0 & 5 & 11 \\
\hline & $9,09 \%$ & $\begin{array}{c}27,27 \\
\%\end{array}$ & $\begin{array}{c}18,18 \\
\%\end{array}$ & $0,0 \%$ & $\begin{array}{c}45,45 \\
\%\end{array}$ & \\
\hline \multirow[t]{2}{*}{ Large } & 4 & 4 & 9 & 4 & 15 & 36 \\
\hline & $\begin{array}{l}11,11 \\
\%\end{array}$ & $\begin{array}{c}1,11 \\
\%\end{array}$ & $25,0 \%$ & $\begin{array}{c}11,11 \\
\%\end{array}$ & $\begin{array}{c}41,67 \\
\% \\
\end{array}$ & \\
\hline All Grou & 7 & 9 & 17 & 8 & 31 & 72 \\
\hline
\end{tabular}




\section{Discussions and implications}

This section serves as a link between the literature review and the research findings. The aim is to determine if the research agrees or disagrees with the literature. Thereafter, possible reasons for this will be identified as well as the researchers' understanding of the situation.

\section{Outsourced functions}

Dibbern et al. (2004) states that the most common ICT functions being outsourced include project management, systems and network implementation, and business and systems analysis. The results of the current study seemingly contradict various findings of these researchers. However network implementation seems to be consistent with Dibbern et al. (2004).

Two highly outsourced functions include software development and hardware implementation. This is in line with the generalisation that many organisations implement information systems in their organisation to gain a competitive advantage, but do not have the expertise to do it themselves. The requirements of a system are actual software programs and hardware to run it and this could be the motivation behind these functions being the most outsourced functions. The study by Scardino et al. (2005) is in agreement with the current study, revealing that network outsourcing is popular due to the optimisation of infrastructures which allows organisations to focus on their core business functions and reduce costs.

\section{Influencing factors}

According to Costa (2001), Goo et al. (2000) and Meyers (2002), the factors that influence the outsourcing decision have evolved from being based on cost to more strategic decisions within the organisation. Benamati and Rajkumar (2002) as well as Fink and Shoeib (2003) have indicated that the organisation concentrating on its core activities could influence its outsourcing decision. The research findings of this study reinforce the findings of the above researchers.

In this study, cost is seen as being the most influencing factor in the outsourcing decision. Organisations are, however, also moving towards the outsourcing of smaller business functions so that they can concentrate on their core business activities. This was observed as the second most influential factor from this study. The motivation behind this is that for organisations to remain competitive, they need to concentrate on their core functions and capitalise on their speciality. Thus organisations that follow this practice outsource the less important, smaller more facilitative functions of the business.

This research has shown that in-house expertise is the third most influential factor. Costa (2001) explains that developing in-house skills or attracting individuals with the necessary skills is costly and time consuming. This would explain why it is so important to take it into consideration. It would save the organisation a lot of costs to outsource when the skills are not available in-house.

\section{Forms of outsourcing}

In a survey conducted by Serafini et al. (2003), 44\% of respondents used co-sourcing, as the benefits derived included specialised knowledge and technical skills. According to Cantara et al. (2005), Application Service Providers (ASP) are becoming popular amongst organisations of all sizes. This is due to the fact that there is a great level of satisfaction with organisations using ASPs (Huntley, 2006).

The research findings have shown that co-sourcing only contributes to $24 \%$ of the outsourcing, while ASPs account for $42 \%$ of outsourcing. This contradicts what the literature of Cantara et al. (2005) and Huntley (2006) has shown, i.e. ASPs are the most used form of outsourcing while cosourcing is the second most used form of outsourcing.

\section{Size vs outsourcing decisions}

According to Coward (2003), outsourcing decisions within small-to-medium organisations are driven by similar factors to large organisations. They do, however, differ with regards to what they outsource. Coward (2003) makes specific reference to software development outsourcing.

The research findings agree with the first statement about influencing factors but disagree with the second statement regarding outsourced business functions. According to this study there is no correlation between the size of the organisation and the factors influencing all organisations. Furthermore, no correlation to the outsourced functions has been observed in this study. The literature states that software development outsourcing is affected by the size of the organisation. However, the statistical analysis of this study has not indicated any correlation.

The lack of association between the size of the organisation and outsourced ICT business function or influencing factors indicates that all organisations sizes are affected by outsourcing. This further infers that their outsourcing decisions the same.

\section{Type vs outsourcing decisions}

The type of the organisation only plays a small part when it comes to making outsourcing decisions. Organisations that outsource are usually those that have a low technology culture and lack technological skills and skills required (Costa, 2001).

However the outsourced function of Network Implementation is not in agreement. This study indicates no correlation between the type of the organisation and influencing factors or outsourced functions, except with regards to Network Implementation.

No correlation between the type of the organisation and outsourced ICT business function or influencing factors means that all organisations types are affected by, and treat their outsourcing decisions in the same way. 


\section{Size vs form of outsourcing}

Coward (2003) claims that small-to-medium organisations typically outsource to vendors within their country (insourcing) as they require close cooperation between themselves and the vendor.

The research findings reveal that there was no relation between the size of the organisation and which form of outsourcing they used. This is in contrast to the literature. There is also no association between the size of the organisation and which form of outsourcing they use, signifying that all organisation sizes generally use the same forms of outsourcing. This suggests that the trend should continue, and since ASPs are leading the market due to their impeccable service and benefits, they should continue to be the primary providers of outsourcing.

\section{Conclusion}

This empirical research was conducted to determine how South African organisations view their outsourcing; what they outsource and what influences their outsourcing decisions. The aim was then to determine if there were any relationships between the size/type of the organisation and their outsourcing decisions.

Compared to the literature, the research findings revealed many contradictory facts about the outsourced functions that were unforeseen. The literature was taken from an international perspective, while the results were obtained from South African organisations. This could mean that South Africa is not in line with international outsourcing opinion.

Understandably, cost is the most influential factor when making a decision with regards to outsourcing. As with any acquisition, cost is considered as the most important factor, thus instantiating the findings of cost being the most important determinant in an outsourcing decision.

Outsourcing is not influenced by organisational size or type; findings have shown that it is the same across all organisation sizes and types. Similarly, the form of outsourcing used is also not affected by the size of the organisation.

This research has shown that outsourcing decisions are not affected or influenced by any of the variables tested in this empirical research. According to Benamati and Rajkumar (2002), many outsourcing decisions are based on prior outsourcing experiences. The findings revealed no correlation in any of the hypothesis tests; size/type of the organisation does not affect the outsourcing decision. This may be due to the fact that organisations base there outsourcing decisions on their prior experiences and explains why the size/type of the organisation did not influence their outsourcing decisions. It can thus be deduced that each organisation finds the best outsourcing strategy to satisfy their needs based on their past experiences.

\section{Recommendations for future research}

The results obtained in the research might not be a true reflection or accurate assessment of the outsourcing industry in South Africa. These results could be attributed to the following areas identified. Recommendations to improve this study have been identified below.

\section{Increase sample size}

The current sample consisted of seventy-two respondents. The sample size could have caused inconsistency with the existent literature. A recommendation is to increase the sample size, which will allow a more thorough assessment of the actual situation in South Africa with regards to outsourcing.

\section{Equal distribution of organisational sizes}

The majority of the replies were from large organisations and there were very few replies from small organisations. A better distribution of organisation sizes would have reflected the results more accurately. It is suggested that a minimum sample size be at least 200 for each size of organisation.

\section{Equal distribution of organisational types}

There was a considerable difference between the amounts of replies from the different types of organisations. The distribution was not even and thus sufficient tests on the data could not be conducted. Future research should include a more even distribution of various types of organisations to render the results more impartial.

Increasing sample size, with more of each size and type of organisation should improve the integrity of the data and consequently the results.

\section{Evaluate future trends in outsourcing}

Despite India's popularity in the outsourcing market, organisations continue to seek for other inshoring opportunities. This aspect was excluded from this study, but could prove to be a worthy aspect for future outsourcing research.

\section{Examine the outsourcing opportunities within South Africa}

Currently, as neither a developed nor a developing country, South Africa has not gained similar benefits from outsourcing to that of countries like the US and India. South African outsourcing vendors have not made noticeable progress with regards to the supply of outsourcing services like that of countries like India. Future research has to be conducted to determine why a transitional country like South Africa is not on the frontline of the outsourcing market. 


\section{References}

Anderson, D.S. 2006. Dealing with dissatisfaction in application outsourcing. Stamford: Gartner Research.

Benamati, J. \& Rajkumar, T.M. 2002. 'A design of an empirical study of the applicability of the technology acceptance model to outsourcing decisions'. Proceedings of the 2002 ACM SIGCPR conference on Computer personnel research, Kristiansand, Norway.

Beulen, E. \& Ribbers, P. 2003. 'IT outsourcing contracts: Practical implications of the incomplete contract theory'. 36th Annual Hawaii International Conference on System Sciences. Hawaii.

Bloch, M. \& Spang, S. 2003. 'Reaping the benefits of business-process outsourcing'. [online] URL: http://www.mckinsey.ch/_downloads/aboutus/MCKonIT_10 .03_bpo.pdf.

Blumberg, B., Cooper, D. R. \& Schindler, P. S. 2005. Business research methods. New York: McGraw-Hill.

Brody, R., Miller, M. \& Rolleri, M. 2004. 'Outsourcing income tax returns to India: Legal, ethical, and professional issues', CPA Journal, 74 (12):12-14.

Brown, R.H. \& Karamouzis, F. 2005. 'Assess the 'nearshore' advantages for business process outsourcing. Stamford: Gartner Research.

Cantara, M., Scardino, L., Karamouzis, S., Brown, R.H., Da Rold, C., Igou, B., Young, A., Soejarto, A., Goodness, E., Clark, L.M., Ambrose, C., Chamberlin, T., Goldman, M., Matlus, R.T. \& Lee, M. 2005. Hype cycle for IT services. Stamford: Gartner Research.

Carr, S. 2005. 'Next up for offshoring: SMEs. The benefits go beyond cost.' [online] URL:

http://www.silicon.com/research/specialreports/sme/0,38000 04380,39128620,00 htm.

Connor-Linton, J. 2003. 'Chi Square tutorial'. [online] URL:http://www.georgetown.edu/faculty/ballc/webtools/we b_chi_tut.html\#overview.

Costa, C. 2001. 'Information technology outsourcing in Australia: A literature review', Information Management \& Computer Security, 9(5):213-224.

Coward, C.T. 2003. 'Looking beyond India: Factors the shape the global outsourcing decision of small and medium sized companies in America', The Electronic Journal of Information Systems in Developing Countries, 13(11):1-12.

Cullen, S. \& Willcocks, L. 2003. Intelligent IT outsourcing: Eight building blocks to success. Burlington: ButterworthHeinemann.

Cusmano, L., Mancusi, M.L. \& Morrison, A. 2006. 'Globalisation of production and innovation: How outsourcing is reshaping an advanced manufacturing area’,
Proceedings of the International ProAct Conference Innovation Pressure.

Da Rold, C., Jester, R. \& Young, A. 2005. The future of outsourcing. Stamford: Gartner Research.

Dibbern, J., Goles, T., Hirschheim, R. \& Jayatilaka, B. 2004. 'Information systems outsourcing: A survey and analysis of the literature', Database for Advances in Information Systems, 35(4): 6-102.

DiRomualdo, A. \& Vijay, G. 1998. 'Strategic intent for IT Outsourcing’, Sloan Management Review, (July) 15: 67-80.

Drezner, D.W. 2004. 'The outsourcing bogeyman', Foreign Affairs, 83(3):22.

Elmuti, D., Kathawala, Y. \& Monipallil, M. M. 1998. 'Outsourcing to gain a competitive advantage', Industrial Management, 40(3): 20-24.

Erber, G. \& Sayed-Ahmed, A. 2005. 'Offshore outsourcing: Global shift in the present IT industry', Intereconomics, 40(2):100-112.

Fink, D. \& Shoeib, A. 2003. 'Action: The most critical phase in outsourcing information technology', Logistics Information Management, 16 (5):302-311.

Fulbright, R. \& Routh, R.L. 2004. 'How information technology professionals keep from being outsourced or offshored'. Proceedings of the the 5th conference on Information technology education, Salt Lake City, UT, USA.

Goles, T. \& Chin, W.W. 2005. 'Information systems outsourcing relationship factors: Detailed conceptualization and initial evidence', ACM SIGMIS Database, 36(4):47-67.

Goo, J., Kishore, R. \& Rao, H.R. 2000. 'A content-analytic longitudinal study of the drivers for information technology and systems outsourcing'. Proceedings of the twenty first International Conference on Information Systems, Brisbane, Queensland, Australia.

Hart, M. 2006. 'Some basic statistical tests in "Statistica for Dummies” format'. Lecture notes Information Systems Honours course, at University of Cape Town, Cape Town.

Hormozi, A., Hostetler, E. \& Middleton, C. 2003. Outsourcing information technology: Assessing your options. [online] URL:

http://www.chusho.meti.go.jp/sme_english/whitepaper/1999 /chapter3.html

Huntley, H. 2005. Offshore sourcing demands new governance models. Stamford: Gartner Research.

Huntley, H. 2006. Fifteen ways to reduce risk when building an offshore outsourcing contract. Stamford: Gartner Research. 
Iyengar, P., Karamouzis, F., Marriott, I. \& Young, A. 2006. Magic quadrant for offshore application services. Stamford: Gartner Research.

Ketler, K., \& Willems, J. R. 1999. 'A study of the outsourcing decision: Preliminary results', ACM SIGCPR conference on Computer personnel research, New Orleans.

Knight, R. 2006. 'The displacement effects of gambling in South Africa'. Unpublished Masters in Business Administration. Cape Town: University of Cape Town.

Koulopoulos, T.M. 2004. Smartsourcing: Doing more with less. A white paper. Perot Systems Though Leadership Board, Perot Systems Group.

Lee, J.N., Huynh, M.Q., Chi-Wai Kwok, R. \& Pi, C.S.M. 2003. IT outsourcing evolution --- past, present, and future. New York: ACM Press.

Maxwell, C. 2008. 'Foreign investment in South Africa'. [online] URL:

http://www.homecomingrevolution.co.za/index.php?option= com_content\&task=view\&id=568.

Meyers, J.T. 2002. Why organisations outsource services: Opportunities and challenges. Stamford: Gartner Research.

Minevich, M., \& Richter, F. 2005. 'Global outsourcing report 2005'. [online] URL:

http://www.globalequations.com/Global\%20Outsourcing\%2 0Report.pdf.

Olsen, K. B. 2006. Productivity impacts of offshoring and outsourcing: A Review. Working Paper, OECD Directorate for Science, Technology and Industry (STI). Paris: OECD.

Parlov, I. 2004. 'The influence of outsourcing on achieving business goals in large Croatian organisations', Management, 9: 47-72.

Ramanujan, S. \& Jane, S. 2006. 'A legal perspective on outsourcing and offshoring', Journal of American of Business, 8(2):51-58.

Serafini, R., Sumners, G.E., Apostolou, B. \& Lafleur, L. 2003. 'A fresh look at cosouring', Internal Auditor, 60(5): 61-65.

Sargent, A. 2006. 'Outsourcing relationship literature: An examination and implications for future research'. Proceedings of the ACM SIGMIS CPR conference on computer personnel research Claremont, California, USA.

Scardino, L., Anderson, D.S., Brown, R.H., Da Rold, C., Dreyfuss, C., Karamouzis, F., Lovelock, J.D., Maurer, W., Moore, C. \& Young, A. 2005. Gartner on outsourcing. Stamford: Gartner Research.

Scardino, L. \& Young, A. 2005. How to make better application outsourcing decisions. Stamford: Gartner Research.
Thoms, B. 2004. 'Inside out and outside in'. Thesis. Stevens Institute on Technology. Hoboken, New Jersey, USA.

Verhoef, C. 2004. 'Quantitative aspects of outsourcing deals', Science of Computer Programming, 56 (2005): 275313.

Waller, A. 2004. 'Supply chain management and logistics outsourcing - Trends in the UK'. [online] URL: http://www.touchbriefings.com/pdf/976/5_waller.pdf.

Wonseok, O.H., Gallivan, M.J. \& Kim, J.W. 2006. 'Find more like this. The market's perception of the transactional risks of information technology outsourcing announcements', Journal of Management Information Systems, 22(4): 271-303.

Wright, T. 2005. 'Outsourcing financial services authority report on offshoring', Computer Law \& Security Report, 21: 500-504.

Young, A., Scardino, L., Karamouzis, S., Marriott, I. \& Iyengar, P. 2005. User guide for making application outsourcing provider choices. Stamford: Gartner Research. 